Fukushima J. Med. Sci.,

Vol. 57, No. 2, 2011

[Case Report]

\title{
TWO CASES OF THORACIC EPIDURAL NEUROLYSIS AFTER LOCAL ANESTHETIC TITRATION IN CANCER PATIENTS
}

\author{
KAORU TAKAHASHI-SATO, KOTARO HASHIMOTO, YUKO NAKANO, \\ MIDORI MOGAMI, MARIKO MUTO, \\ MASAYUKI NAKAGAWA and MASAHIRO MURAKAWA
}

Department of Anesthesiology, Fukushima Medical University School of Medicine, Fukushima, JAPAN

(Received July 20, 2011, accepted September 7, 2011)

\begin{abstract}
Two patients who underwent thoracic epidural neurolysis after titration using local anesthetic are reported. Case 1 suffered serious back and epigastric pain arising from metastasis of lung cancer and Case 2 was not relieved right chest pain by costal metastasis from urethral cancer only by morphine. Block therapies improve the patients' quality of life if these underwent in opioid resistant pain or moving pain. Among them subarachnoid neurolytic blockage or epidural continuous blockage are usually selected in terminal stage. Subarachnoid blockage is potent but usually induces paresthesia and hypesthesia and patient has to keep lateral position under affected site intraoperatively. Epidural block is easy to treat but is difficult to continue because of infection and decrement of efficacy attributed adhesion of epidural space, stress arose from immobilization. We operate epidural neurolytic blockage for these patients and they were relieves from pain without suffer from the side effect.
\end{abstract}

Key words : cancer pain, thoracic epidural neurolysis, ethyl alcohol

\section{INTRODUCTION}

Although it is said that $90 \%$ of cancer pain is relieved by using opioids according to the World Health Organization's algorithm, nerve blocks have been effective method for opioid resistant pain such as neuropathic one ; e.g. compression or invasion of nervous tissue by tumors. Of those of blockade, neurolytic blocks are suitable for the patients with short life expectancy. However, some patients received neurolytic blocks for pain relief could not endure hypesthesia or motor paresthesia.

We report two cases that were reduced intolerable cancer pain without any adverse effects using the thoracic epidural alcohol block after local anesthetic titration.

CASE 1

A 62-year-old man, who was diagnosed with lung cancer and brain metastasis and treated by radiotherapy respectively. In 65 years old, metastasis to right hilar lymph node and right adrenal gland were identified and then received radiotherapy. Six months later, right shoulder and hypochondriac pain had appeared and the pain extended to the right back. He started to take sustainedrelease morphine sulfate $40 \mathrm{mg} /$ day ; he could not endure the pain without taking morphine sulfate 160 $\mathrm{mg} /$ day and $25 \mathrm{mg}$ of diclofenac sodium suppository every 3-4 hours. Then he admitted to our hospital, morphine hydrochloride was administered intravenously and was titrated with $144 \mathrm{mg}$ /day to alleviate the pain. However, he suffered from respiratory depression. We contemplated the applicability of neurolytic nerve block. Because the patient was very nervous not to endure hypesthesia caused by subarachnoid phenol block, he preferred to perform epidural alcohol block. Epidural catheter was inserted from Th8/9 level and $2 \%$ of lidocaine hydro-

佐藤 薰, 橋本孝太郎, 中野裕子, 最上 翠, 武藤茉莉子, 中川雅之, 村川雅洋

Corresponding author: Kaoru Takahashi-Sato, MD, PhD E-mail address : kaoru-t@fmu.ac.jp

http://www.jstage.jst.go.jp/browse/fms http:/fmu.ac.jp/home/lib/F-igaku/ 
Case 1

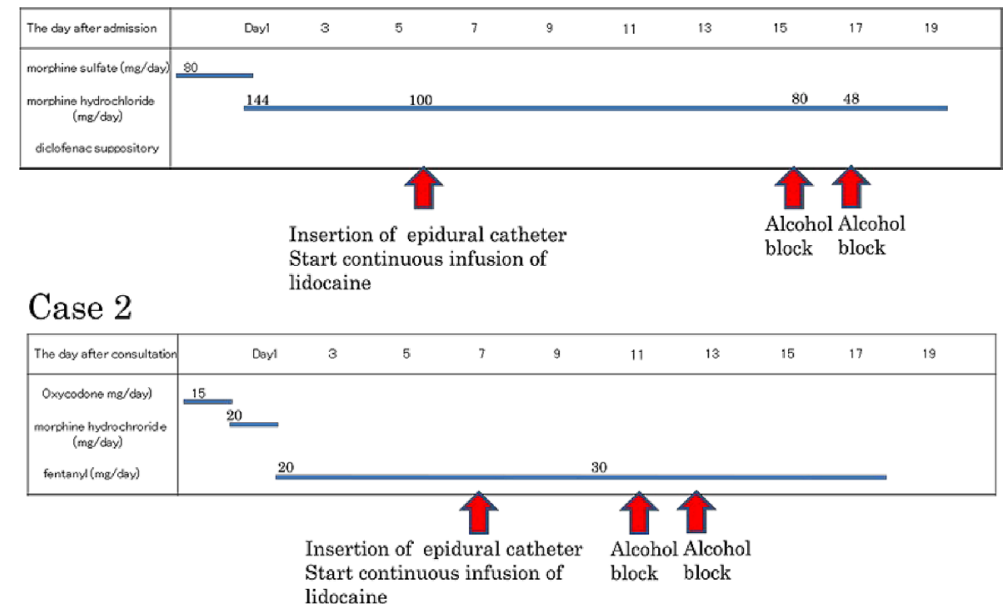

Fig. 1. Time course of consumption of analgesics mainly opioid in case 1 and case 2. The amount of each opioid analgesics are unified to titer of morphine intravenously. In case 1, after epidural neurolysis the opioid analgesic consumption was decreased in a half. Meanwhile the pain in motion was alleviated after the treatment, the dosage of opioid was not changed in case 2 .

chloride was infused $2 \mathrm{ml} / \mathrm{h}$ for 24 hours. We ascertained whether the range affected by the epidural block match to the painful area next day. The third day, $1 \mathrm{ml}$ of absolute ethyl alcohol was administered from epidural catheter over $5 \mathrm{~min}$, followed by the infusion with a speed of $1 \mathrm{ml} / \mathrm{h}$ for 2 hours. After 1 hour interval, same procedure was repeated two times. The patient was positioned supine throughout the infusion and resting interval. As the efficacy of the block was not enough to cover the painful area, the speed of administration was gained to 2 $\mathrm{ml} / \mathrm{h}$ for two hours in the third procedure. The next day, absolute alcohol was administered at the speed of $2 \mathrm{ml} / \mathrm{h}$ for 2 hours after $1 \mathrm{ml}$ of single injection at 1-hour interval for 3 cycles. At completion of the alcohol infusion, the catheter was removed after a flushing $0.5 \mathrm{ml}$ of $1 \%$ lidocaine hydrochloride. Finally sensory function in the Th8-9 dermatome was declined and consumption of continuous intravenous morphine administration was decreased to $48 \mathrm{mg}$ /day. In the course of epidural alcohol administration, severe side effects were not occurred without pain caused by primary dosage of alcohol which was alleviated by single dose of diclofenac sodium suppository. Next day intravenous morphine administration was changed to oral sustainedrelease morphine sulfate and discharged the seventh day from admission. One month later the hypochondriac pain relapsed. Although he underwent celiac plexus neurolytic block, he continued to take diclofenac sodium suppository 6-7 times per day and died five months later after celiac plexus neurolytic block.

\section{CASE 2}

A 63-year-old man, who was diagnosed with urethral cancer and underwent the amputation of penis and the radiotherapy at stump of penis and inguinal lymph node. Six months later, metastasis to the right pleura and lung with the rib invasion were identified and he underwent chemotherapy. Although he began to take $20 \mathrm{mg}$ of sustainedrelease oxycodone tablets, the perineal pain and right chest pain had exaggerated to admit our hospital. The intravenous administration of morphine hydrochloride $20 \mathrm{mg} /$ day could not reduce the pain at all but induced respiratory depression. As the patient complicated renal dysfunction, we altered morphine administration to fentanyl citrate. The perineal pain was relieved, but he could not sit still and keep lateral position under affected site for a while because of right chest pain. So we scheduled epidural alcohol block. We inserted catheter from Th6/7 and administered 2\% lidocane hydrochloride by $2 \mathrm{ml} / \mathrm{h}$. The next day it was confirmed whether the area of hypesthesia suits the affected site. Then, $1 \mathrm{ml}$ of absolute alcohol was administered from epidural catheter over $5 \mathrm{~min}$ followed by the infusion of $2 \mathrm{ml} / \mathrm{h}$ for 2 hours, three times with 1 hour intervals. The next day, same procedures were repeated three times. After the procedures of epidural alcohol block, the hypesthesia was seen in the area of Th4-7. The injection pain appeared at the initial alcohol administration, which could be alleviated by a single administration of fentanyl citrate, but gradually disappeared. The next day 
after completion of epidural alcohol block, he did not complain the chest pain and could sit still on the bed. The seventh day he discharged the hospital and received home care. He died two days after discharge without pain.

\section{DISCUSSION}

We could perform pain relief with epidural alcohol block in two advanced cancer cases without any sever adverse events.

Neurolytic blocks are suitable for patients with short life expectancy and well-localized intractable pain because it might increase the patient' disability through motor weakness, incontinence, sexual dysfunction, or position sense. Epidural neurolysis may have an advantage over subarachnoid neurolysis in cervical and upper thoracic areas as neurolytic agent does not diffuse in CSF-containing subarachnoid space. The epidural alcohol block has been tried from 80 years ago ${ }^{1,2)}$. However epidural neurolytic techniques are rarely used, and generally considered second-line therapies behind spinal analgesic therapies. The usefulness of alcohol administration into the epidural space had been controversial $^{3-7)}$; it was attenuated because of alcohol neuritis, persistency of block, and so on. If we could control the affected nerves by alcohol like local anesthetics' differential blockade, we might alleviate pain certainly without paresthesia and/or hypesthesia. Yamamuro described the titration method with local anesthetics preceded the alcohol administration in the caudal approach to treat the perineal pain with rectal cancer ${ }^{7}$. In these cases reported here, we could confirm the usefulness of this titration method in thoracic epidural alcohol neurolysis.

Duration of effectiveness by a single dose alcohol was reported average 54 day - 44 months $^{8}$. That was interpreted epidural alcohol block does not keep for a long time. So we tried alcohol block three times a day for three days. In this course only pain passed away as administrating alcohol and any other adverse effect was not seen. The duration of effectiveness of epidural alcohol block in these cases is not clear, because case 2 died three days after discharge and case 1 underwent celiac plexus alcohol block one month after the epidural alcohol block.

We have to contemplate adaptation of nerve block and choose regarding adverse effect. The most patients, who received subarachnoid phenol block to treat the intractable pain in the thoracic nerve area, did not endure hypesthesia. So, epidural alcohol block should be reevaluated for the useful tool for the patients who are suffering from cancer pain in the thoracic region.

\section{REFERENCES}

1. Woodbridge PD. Therapeutic nerve block with procaine and alcohol. Am J Surg, 9 : 278-288, 1930.

2. Gilcrest EL, Mullen TF. The epidural and transsacral injection of alcohol for the relief of pain. Surg Clin North Am, 11 : 989-994, 1931.

3. Odom CB. Epidural anesthesia in resume and prospect. Anesth Analg, 19 : 106-108, 1940.

4. Bromage PR. Extradural analgesia for pain relef. Br J Anaesth, 39 : 721-729, 1967.

5. Racz GB, Sabonghy M, Gintaitas J, et al. Intractable pain therapy using a new epidural catheter. JAMA, 248 : 579-581, 1982.

6. Coombs DW. Potential Hazards of Transcatheter Serial, 1985.

7. Yamamuro M. epidural blockage. In: Yamamuro M, Kaneko T, editors. Zusetu itami-nochiryo-nyumon, $3^{\text {rd }}$ Edition, Tokyo, Cyugaiigakusha, 152-153, 1997.

8. Korevaar WC. Transcatheter thoracic epidural neurolysis using ethyl alcohol. Anesthesiology, 69 : 989-993, 1988. 